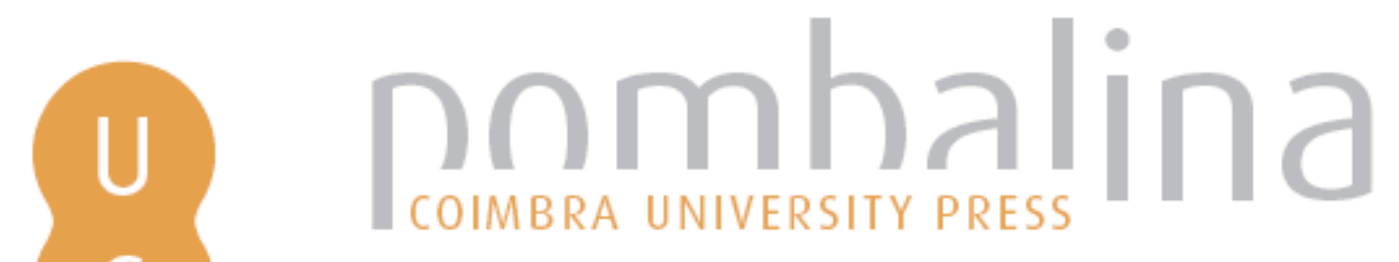

Em direcção à "grande unificação» de composição, análise e execução musicais

Autor(es): Mazzola, Guerino

Publicado por: Imprensa da Universidade de Coimbra; Gravida

URL

persistente: URI:http://hdl.handle.net/10316.2/32619

DOI: $\quad$ DOI:http://dx.doi.org/10.14195/978-989-26-0485-5_15

Accessed : $\quad$ 26-Apr-2023 11:18:52

A navegação consulta e descarregamento dos títulos inseridos nas Bibliotecas Digitais UC Digitalis, UC Pombalina e UC Impactum, pressupõem a aceitação plena e sem reservas dos Termos e Condições de Uso destas Bibliotecas Digitais, disponíveis em https://digitalis.uc.pt/pt-pt/termos.

Conforme exposto nos referidos Termos e Condições de Uso, o descarregamento de títulos de acesso restrito requer uma licença válida de autorização devendo o utilizador aceder ao(s) documento(s) a partir de um endereço de IP da instituição detentora da supramencionada licença.

Ao utilizador é apenas permitido o descarregamento para uso pessoal, pelo que o emprego do(s) título(s) descarregado(s) para outro fim, designadamente comercial, carece de autorização do respetivo autor ou editor da obra.

Na medida em que todas as obras da UC Digitalis se encontram protegidas pelo Código do Direito de Autor e Direitos Conexos e demais legislação aplicável, toda a cópia, parcial ou total, deste documento, nos casos em que é legalmente admitida, deverá conter ou fazer-se acompanhar por este aviso.

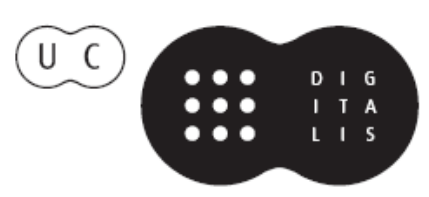


(Página deixada propositadamente em branco) 
MARIA PAULA SERRA DE OLIVEIRA

Coordenadora

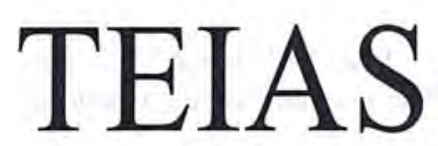

MATEMÁTICAS

Frentes na Ciência e na Sociedade 
(C) Gradiva - Publicações, L. da / Imprensa da Universidade de Coimbra, 2004 Coordenação editorial: Maria Paula Serra de Oliveira

Tradução: Artur Soares Alves

Carlota Isabel Leitão Pires Simões

Francisco José Craveiro de Carvalho

João Filipe Cortez Rodrigues Queiró

José Miguel Dordio Martinho de Almeida Urbano

Lia Sandra dos Santos

Mário da Silva Rosa

Paulo Eduardo Aragão Aleixo Neves de Oliveira

Revisão do texto: Isabel Pedrome

Capa: António Barros [Imprensa da Universidade. Coimbra], com imagem de

E. M. de Melo e Castro, "Fract 010 explod MC", Dezembro de 2003

[Fractal original gerado no Fractint com tratamento no Photoshop 7.0]

Infografia: Estúdios Estímulus [design]

Paginação: António Resende e Victor Hugo Fernandes

Impressão e acabamento: G.C. - Gráfica de Coimbra, L. da

Reservados os direitos para Portugal por:

Gradiva - Publicações, L. ${ }^{\text {da }}$ e Imprensa da Universidade de Coimbra

Gradiva - Publicações, L. ${ }^{d a}$

Rua Almeida e Sousa, 21, r/c, esq. • 1399-041 Lisboa

Telefs. $213974067 / 8 \cdot 213971357 \cdot 213953470$

Fax $213953471 \cdot$ Email: gradiva@ip.pt

URL: http://www.gradiva.pt

Imprensa da Universidade de Coimbra

Rua Antero de Quental, 195 • 3000-033 Coimbra

Telefs. 351239853110

Fax 3512398531 19 e-mail: fjrpress@ci.uc.pt

URL: http://www.imp.uc.pt

ISBN: 972-662-970-5

1." edição: Maio de 2004

Depósito legal n. ${ }^{\circ} 210431 / 04$

OBRA PUBLICADA COM O PATROCÍNIO DE:

CENTRO DE MATEMÁTICA DA UNIVERSIDADE DE COIMBRA DEPARTAMENTO DE MATEMÁTICA DA UNIVERSIDADE DE COIMBRA

FCT Fundação para a Ciência e a Tecnologia

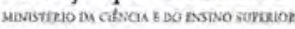


Guerino Mazzola

University and ETH Zurich, Suiça

Internet Institute for Music Science

\section{Em direcção à «grande unificação» de composição, análise e execução musicais ${ }^{1}$}

A matemática do século XX deu origem a um processo dramático de reescrita de teorias musicais e correspondente tecnologia da informação. Apresentamos uma visão geral dos modelos de harmonia e contraponto que foram concebidos neste espirito. Baseadas numa teoria matemática da representação unificada de objectos musicais, estas teorias foram implementadas em programas informáticos e aplicadas à análise, composição e execução musicais. Esta representação unificada baseia-se em disciplinas da matemática moderna tais como a teoria dos topos, a lógica e a geometria, bem como em paradigmas de programação orientada para objectos. Os métodos matemáticos utilizados nesta descrição de fenómenos musicais incluem a teoria de módulos, a combinatória, a geometria algébrica, a estatística, os campos de vectores, as equações diferenciais ordinárias, as equações às derivadas parciais e a topologia algébrica. A unificação não só tem em conta a representação de objectos musicais e o tratamento unificado dos processos específicos, como em última análise aponta para uma fusão de verdade e beleza.

${ }^{1}$ Tradução de Carlota Simões, professora do Departamento de Matemática, Universidade de Coimbra. 


\section{INTRODUÇ̃̃̃o}

«Grande unificação» é uma expressão proveniente da física das partículas e representa a ideia de que três das quatro forças básicas: forte, fraca e interacção electromagnética são descritas como instâncias especiais de uma única super força subjacente ${ }^{2}$. A alusão a este paradigma tem como objectivo estabelecer uma relação entre tendências e resultados até agora considerados campos dispersos e não relacionados da música e da musicologia, tais como

- a representação de objectos musicais de natureza muito diferente, tais como notas de uma partitura, acontecimentos de sons físicos, acordes, motivos, ritmos, formas de natureza mista, agrupamentos de objectos musicais tal como eles intervêm em simbolos de agrupamento utilizados em partituras (ligaduras, por exemplo), e estruturas de execução tais como hierarquias de tempo;

- a teoria de funções de Riemann ${ }^{3}$ em harmonia e a teoria de contraponto de Fux;

- a análise musical de melodias e ritmos;

- a teoria da execução e da análíse musical;

- os espaços de afinação para representação de notas.

Isto apenas para mencionar alguns dos aspectos de unificação mais importantes. Neste contexto, não podemos dar mais que um breve esboço destes desenvolvimentos e remeter para o livro The Topos of Music Geometric Logic of Concepts, Theory and Performance (Mazzola, G., et al., 2001) para uma descrição detalhada.

O objectivo principal do presente artigo é apresentar uma teoria matemática para uma parte profunda da natureza humana interior, nomeadamente a música, em contraste com a descrição matemática habitual da natureza exterior em ciências naturais. Mas esta transferência de métodos clássicos para as humanidades não se restringe ả construção de modelos matemáticos; também inclui a metodologia da verificação e falsificação experimentais dos modelos. Isto significa que o processo científico tradicional aplicado nas ciências naturais é reconstruido nas humanidades: experiências de natureza mental tornaram-se uma «alternativa» possivel para a física (ver Mazzola, G., et al., 1998, para uma discussão alargada desta extensão metodológica).

${ }^{2}$ A «teoria do todo» acrescenta ainda a gravidade à grande unificação.

${ }^{3}$ Não confundir o musicólogo Hugo Riemann com o matemático Bernhard Riemann! 


\section{QUANTA PARA MOdULAÇĀO TONAL}

O modelo de modulação a seguir apresentado é uma primeira construção muito simples que, no entanto, conduz a resultados muito precisos e possui a propriedade típica dos modelos matemáticos em música: permitir uma generalização quase automática de situações para as quais a teoria de música clássica para a qual o modelo foi construído não tem qualquer resposta. No caso da modulação que originalmente foi modelada para escalas maiores, a generalização estende-se a escalas de sete notas arbitrárias. Esta é uma propriedade que tem consequências profundas e que discutiremos para o modelo de contraponto abordado no parágrafo seguinte.

\subsection{O princípio antrópico}

A propriedade de extensibilidade de um modelo matemático volta a colocar a teoria da música existente - que ele modeliza - num campo de potenciais teorias fictícias. Este facto situa a factualidade histórica numa relação com os potenciais «mundos da música». A justificação puramente histórica das regras de modulação existentes, por exemplo, não constitui por si só uma fundamentação para esta escolha, o que torna esta abordagem puramente histórica uma base de conhecimento limitada: sabemos que é assim, mas não sabemos porquê, nem porque é que outras possibilidades não são exequíveis. Em contraste, a abordagem matemática fornece um campo de teorias potenciais nas quais a actual teoria da música pode ser questionada em relação às suas possiveis propriedades especiais relativamente a variantes não existentes.

Isto evoca a ideia de Leibniz segundo a qual o mundo existente é o melhor de todos os mundos possíveis: será a teoria da música existente a melhor escolha possível? Ou existirá, pelo menos, uma outra distinta? Em cosmologia, esta ideia foi reformulada sob a designação de «princípio antrópicon (Barrow, J., e Tripler, F., 1986). Este princípio afirma que as leis da física são as melhores possiveis para a existência humana. Mais precisamente (e menos radicalmente), o princípio antrópico consiste em estabelecer um teorema que afirma que uma pequena variação nás constantes fundamentais, tais como a constante gravitacional ou a carga eléctrica de protões e electrões, tornaria imposșivel qualquer complexidade molecular de ordem superior, tal como a que é necessária para a bioquímica do carbono. 


\subsection{Esquema de modulação de Schöenberg}

No seu texto clássico sobre harmonia, Arnold Schöenberg (1911) descreveu a modulação tonal como um processo de três fases: a neutralização, o ponto de viragem para a nova tonalidade e a confirmação cadencial (ver figura 1).

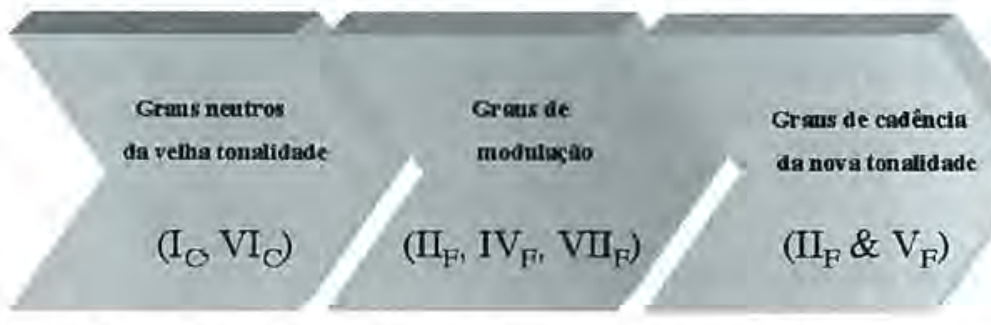

Fig. I-As três fases do esquema de modulação de Schöenberg no caso de uma modulação de dó maior $(C)$ para fá maior $(F)$

A afirmação central refere-se à lista de graus de modulação na fase intermédia ou fase do ponto de viragem. Para criar um modelo matemático devem primeiro definir-se os termos musicológicos e os factos de acordo com uma terminologia matemática rigorosa. Deste modo, temos de responder às seguintes questões:

- Qual é o conjunto de tonalidades admitidas?

- O que é um grau?

- O que é uma cadência?

- Qual é o mecanismo de modulação subjacente?

- Como podem os graus de modulação ser deduzidos a partir de uma resposta às questões anteriores?

Começaremos por trabalhar no contexto da afinação bem temperada, e só iremos considerar notas módulo oitava, ou seja, vamos considerar as doze classes de notas cromáticas, fazendo dó $=0$, dó \# = ré $b=1$, ré $=2, \ldots, s i=11$. Deste modo, o conjunto das classes de notas identificase com o grupo cíclico $Z_{12}$. Consideramos doze escalas diatónicas possiveis, dó $=\{0,2,4,5,7,9,11\}$ (ver figura 2) e as respectivas onze escalas transpostas, fá, si $b$, mi $b, \ldots$, lá, ré, sol, no ciclo das quartas (que se obtém por transposições sucessivas por intervalos de quarta, ou seja, cinco unidades). 

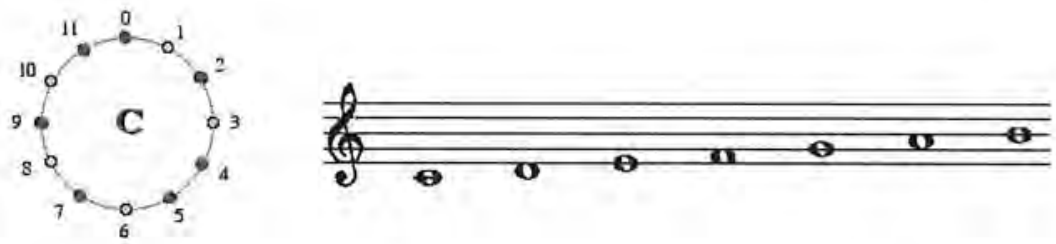

Fig. 2 - A escala de dó maior (C) como um subconjunto de sete elementos do grupo cíclico das doze classes de notas em afinação bem temperada

Para definir uma estrutura de tonalidade numa escala $\mathrm{S}$, consideramos as sete tríades $\mathrm{I}_{\mathrm{S}}, \mathrm{II}_{\mathrm{S}}, \mathrm{III}_{\mathrm{S}}, \mathrm{IV}_{\mathrm{S}}, \mathrm{V}_{\mathrm{S}}, \mathrm{VI}_{\mathrm{S}}, \mathrm{VII}_{\mathrm{S}}$, que são conjuntos de três elementos da escala dada, tal como se mostra para a escala de dó maior (C) na figura 3.

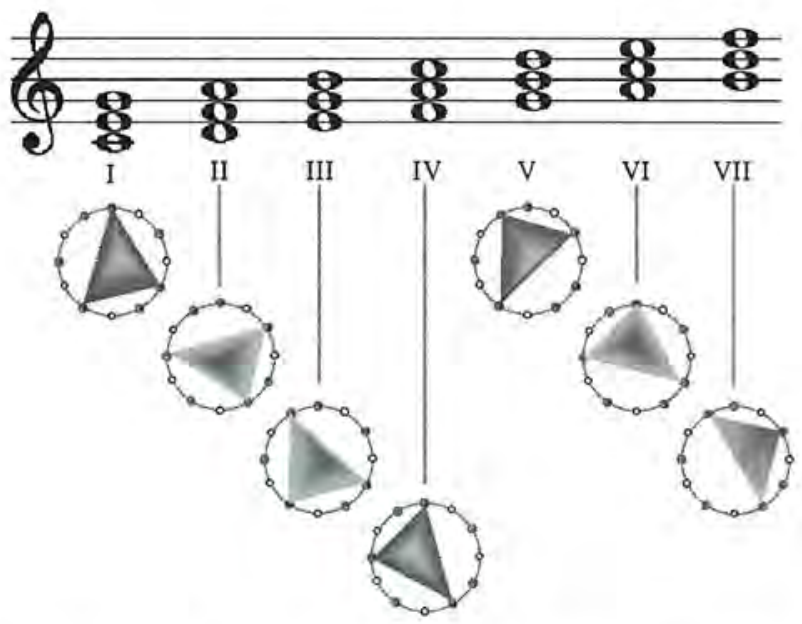

Fig. 3-As triades formadas sobre os sete graus da escala de dó maior definem uma cobertura quase geográfica da escala por cartas

Esta cobertura pode ser comparada a um atlas geográfico cujas cartas são os sete graus. Para construir uma representação englobante da sua configuração em sobreposição mútua, a topologia algébrica introduz o 
conceito de nervo. O nervo desta cobertura é a representação que iremos utilizar na vizualização de tonalidade que a seguir apresentamos. O conceito de nervo é muito simples de compreender, estando os pormenores descritos na figura 5. Primeiro distribuímos as cartas dos graus no espaço (os triângulos pequenos), depois traçamos uma linha entre duas cartas quaisquer que tenham intersecção não vazia. Esta configuração gráfica visualiza o que Schöenberg chama a «banda harmónica» no seu livro Harmony (Schöenberg, 1911). Infelizmente, Schöenberg não deu um passo em frente que seria decisivo: considerar triades dos diferentes graus com intersecção não vazia. Desta vez, desenhamos uma superfície triangular entre quaisquer desses três graus. Verificamos então que o objecto gráfico gerado por este processo é uma bem conhecida fita de Moebius, motivo pela qual se designa por «banda harmónica». Será nesta geometria surpreendente da geografia de tríades que iremos basear a definição de tonalidade ${ }^{4}$.

Sem apresentar mais detalhes, convém notar que a ausência de orientação na banda harmónica (não há de facto distinção entre lado da frente e lado de trás!) é responsável por algumas das maiores desvantagens da teoria de funções harmónicas de Hugo Riemann (Mazzola, G., 1990b).

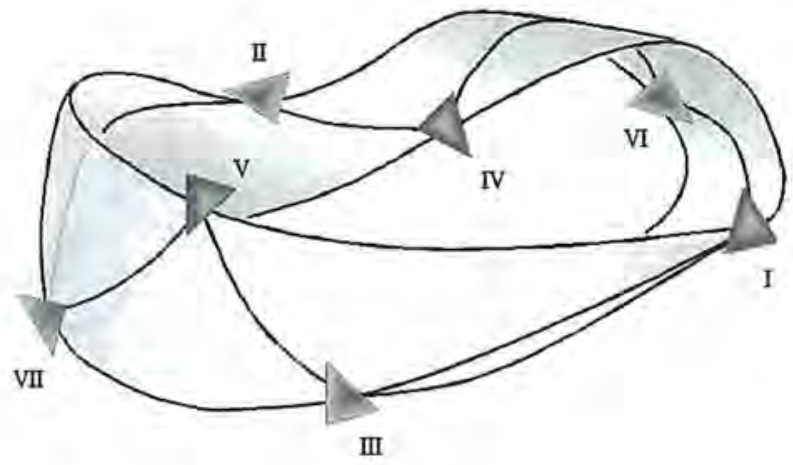

Fig. 4-A banda harmónica é uma fita de Moebius. Matematicamente, é o nervo da cobertura da escala pelos seus sete graus. O grafo das linhas de ligaçâo (sem as superfícies triangulares) entre os graus é a banda harmónica no sentido apontado por Schöenberg (1911)

${ }^{4}$ Notemos que intersecções não vazias de quatro graus diferentes não podem ocorrer, logo estamos nó extremo desta construção de nervo. 
Tendo em conta estas definições e um conceito de cadência, relacionado com conjuntos minimais de graus que definem de modo único a tonalidade envolvente, o mecanismo de modulação da tonalidade S para a tonalidade $\mathrm{T}$ é definido por uma simetria que transforma $\mathrm{S}$ em $\mathrm{T}$. À semelhança do que acontece na física das partículas, materializaremos esta força de transformação por um «quantum de modulação» $M$. Por definição, este é um conjunto de classes de notas, juntamente com uma cobertura por triades de tal modo que a simetria de modulação é uma simetria interior a $\mathrm{M}$, com algumas propriedades técnicas adicionais. A importância deste quantum de modulação reside no facto de ele constituir «matéria musical» - tal como os quanta da modulação física são forças materializadas - , e por isso preconiza um conjunto de graus que devem ser tocados na parte central do processo de Schoenberg apresentado na figura 1 .

O pressuposto central deste modelo de modulação é o seguinte: os quanta de modulação existem para todos os pares de tonalidades e conduzem exactamente aos graus de modulação descritos por Schöenberg (1911). A figura 5 mostra um quantum $M$ para a modulação de dó para mi b. Reconhecemos as duas fitas harmónicas, a claro, bem como o quantum de ligação, a escuro, na representação de nervo. Os graus de modulação são exactamente os vértices de $M$ que se encontram na banda harmónica (quatro graus no exemplo da figura 5) da tonalidade pretendida.

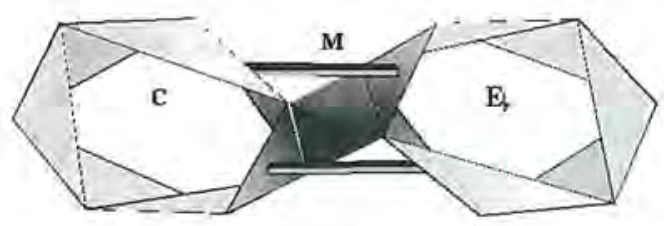

Fig, 5 - Vizualização de um quantum de modulação M para a transição de dó para mi b. A representação de nervo de $M$ mostra a estrutura de conexâo do meio em cor escura, em particular contém dois simplexes de dimensâo 5 (simbolizados por barras horizontais) acima e abaixo do simplex a 3 dimensões (o tetraedro)

Os pressupostos deste modelo e o mecanismo subjacente, nomeadamente a transformação da simetria inerente, podem ser também testados em peças do repertório da música clássica, como, por exemplo, na Opus 106 de Beethoven. Foi possivel obter uma compreensão mais aprofundada dos seus conhecidos planos de modulação, complexos e intrincados, 
oscilando alternadamente entre um «mundo» em torno da tonalidade dominante de si $b$ maior, e um "anti-mundo» em torno da tonalidade de si menor (teses de Erwin Ratz e Jurgen Uhde, Mazzola, G., 1990b).

$\mathrm{O}$ modelo de modulação acima descrito ilustra perfeitamente o "princípio antrópico», um assunto que deriva da modelação matemática. $\mathrm{O}$ modelo pode ser alargado a qualquer escala de sete sons e respectivas bandas harmónicas (Muzzulini, D., 1995), o que permite localizar a escala maior num mundo de potenciais variantes. $\mathrm{O}$ resultado principal neste contexto variacional é que a escala maior ocupa uma posição singular na medida em que o seu arsenal de modulaçâo apresenta o minimo de variedades possivieis entre todas as escalas que admitem modulações entre duas tonalidades quaisquer. A dominação histórica da escala maior encontra assim uma justificação suplementar num quadro perfeitamente sistemático, justificação essa que a abordagem puramente histórica não pode a priori fornecer!

\section{Contraponto via deformaçōes do espaço tangente}

O segundo modelo desta análise, o contraponto clássico, é muito importante por três razões. Em primeiro lugar, ilustra uma vez mais o princípio antrópico; em segundo lugar, torna plausível que seja necessário um quadro conceptual poderoso para enquadrar as sistematizaçôes formais heterogéneas no contexto de uma teoria musical matemática, e em terceiro lugar representa um dos mais interessantes assuntos da actual investigação, a unificação da harmonia e do contraponto. Não iremos abordar esta última questão, mas deve, contudo, ser mencionado que existe um isomorfismo entre uma estrutura central de contraponto e harmonia (ver Noll, Th., 1995).

A teoria matemática do contraponto baseia-se numa representação alternativa das doze classes de notas do modelo de modulação anterior. Mais precisamente, referimo-nos aos doze intervalos musicais, medidos em múltiplos de passos de meio-tom: uníssono $=0$, segunda menor $=1$, segunda maior $=2$, terceira menor $=3$, terceira maior $=4$, quarta $=5$, trítono $=6$, quinta $=7$, sexta menor $=8$, sexta maior $=9$, sétima menor $=10$ e sétima maior $=11$. A oitava é identificada com o unissono módulo oitava, os intervalos maiores que a oitava são identificados com o seu resto módulo oitava, tal como usualmente se faz em contraponto clássico. Assim, o nosso modelo de intervalos é construído a partir da redução módulo oitava. Este conjunto é também visto como o grupo cíclico $Z_{12}$. No entanto, a sua representação prévia num círculo é um tanto 
primitiva, já que não tem em conta a estrutura algébrica relevante. De facto, a chamada decomposição de Sylow (neste caso o teorema de classificação para grupos abelianos finitos) conduz-nos ao produto directo $Z_{12}=Z_{3} \times Z_{4}$. Em termos geométricos, isto significa que temos de pensar num toro (discreto) em vez de num círculo (ver figura 6). Nesta representação, obtêm-se três círculos de terceiras menores, cada um deles a uma terceira maior do seguinte, ou de forma equivalente, quatro círculos de terceiras maiores, cada um deles a uma terceira menor do seguinte. Esta representação algébrica está evidentemente cheia de significado musical, isto é, a decomposição Sylow parece ser a mais adequada para representar classes de intervalos!
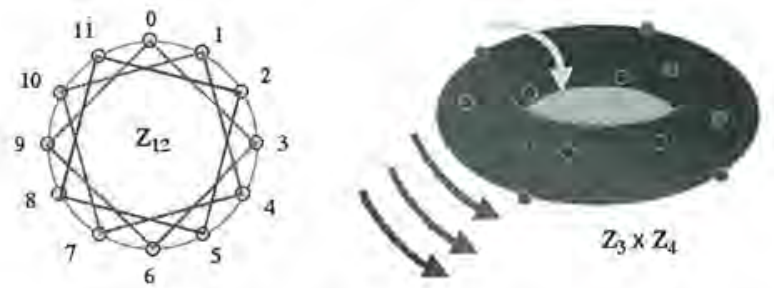

Fig. 6-O conjunto de intervalos $Z_{1 / 2}$ na sua representação Sylow como um produno directo do ciclo de terceiras maiores $Z_{3}$ e do ciclo das terceiras menores $Z_{4}$

Pode verificar-se que a dicotomia contrapontística dos seis intervalos consonantes $\mathrm{K}=\{0,3,4,7,8,9\}$ e dos seis intervalos dissonantes $\mathrm{D}=\{1,2,5,6,10,11\}$ tem uma posição relevante no conjunto de todas as $924^{5}$ dicotomias seis por seis de intervalos (Mazzola, G., 1990b). Note-se que a quarta (intervalo de cinco meios-tons) é dissonante na teoria contrapontística básica, e não consonante, como preconizam os modelos físicos de intervalos. Trata-se de uma diferença importante: uma abordagem genuína da teoria da música não é apenas uma perspectiva física; é um mundo autónomo de entidades simbólicas que privilegia a composição e a construção musicais em vez das restrições acústicas! As propriedades características mais evidentes da dicotomia $\mathrm{K} / \mathrm{D}$ são apresentadas na figura 7. Nesta figura, as duas metades K e D estão

${ }^{5}$ Combinações de doze elementos seis a seis. 
distribuídas no toro de tal modo que se mantêm separadas uma da outra a uma distância máxima, sob condição de que existe uma única simetria afim, nomeadamente $d=5 c+2$, que transforma $K$ em D e vice-versa.
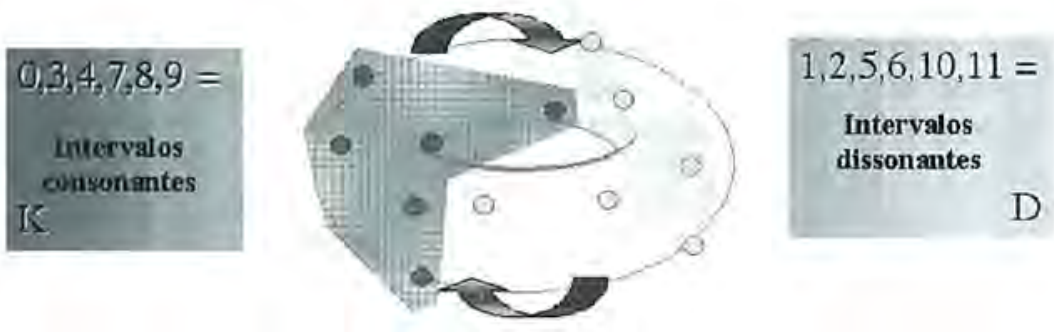

\section{Simetria única $d=5 . c+2$}

Fig. 7 - No toro dos intervalos, as consonâncias $(K)$ e as dissonâncias (D) estão distribuidas de modo caracteristico e distinto: mantêm-se separadas entre si a uma distäncia máxima, sob a condição de que exista uma única simetria afim, nomeadamente $d=5 c+2$, que transforma $K$ em $D$ e vice-versa. Entre todas as possiveis 924 dicotomias seis por seis, esta dicotomia $K / D$ pode ser caracterizada por estas propriedades e pela propriedade da parte consonante $7 k$ (isto $\dot{e}$ quando considerada um conjunto de múltiplos da quinta) ser um monóide multiplicativo

Para além desta representação e caracterização geométricas da medida dos intervalos, a abordagem contrapontística necessita de novos objectos matemáticos: os intervalos vistos como pares, que consistem numa nota de cantus firmus a mais uma quantidade de intervalo $b$, apontando na nota do discantus. Formalizemos estes dados numa representação do intervalo pela expressão algébrica $\mathrm{i}=a+\varepsilon b$. Estritamente falando, referimo-nos ao anel $Z_{12}[\varepsilon]$ dos polinómios $f(\varepsilon)$ com coeficientes no anel $Z_{12}$. Assim, intuitivamente, um intervalo $\mathrm{i}=a+\varepsilon b$ representa o cantus firmus de «ponto base» $a$, juntamente com uma «tangente» infinitesimal $b$ (ver figura 8 para esta geometria tangente).

Os intervalos consonantes definem o subconjunto de 72 elementos $\mathrm{K}=\mathrm{Z}_{12}+\varepsilon \mathrm{K}$, enquanto o seu complementar $\mathrm{D}=\mathrm{Z}_{12}+\varepsilon \mathrm{D}$ define o conjunto dos intervalos dissonantes. Mais uma vez temos essencialmente apenas uma simetria autocomplementar $\mathrm{A}: \mathrm{K} \rightarrow \mathrm{D}$. 

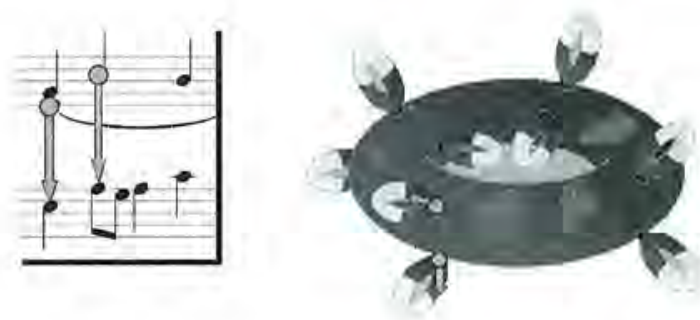

Fig. 8-Os intervalos contrapontísticos são dados por uma nota base de um cantus firmus, juntamente com uma quantidade intervalar direccionada na nota do discantus. Em termos geométricos, podemos interpretar este facto como sendo um vector tangente no toro das classes de notas, sendo a quantidade intervalar a pequena flecha aplicada no ponto base do cantus firmus (esta representação baseia-se na representação de Sylow dos elementos de $Z_{13}$, sejam eles classes de notas ou quantidades intervalares). As pontas das setas dos intervalos consonantes estão na metade $K$ do intervalo consonante (metade escura),

enquanto as dos intervalos dissonantes estão na metade clara dos pequenos toros

O modelo de contraponto baseia-se na seguinte ideia: em contraponto elementar é apenas permitido passar de um intervalo consonante para outro. Assim, por exemplo, uma sequência $2+\varepsilon 3,4+\varepsilon .5$ não é permitida porque termina numa quarta dissonante. A teoria elementar, tal como foi concebida por Johann Joseph Fux no seu famoso Gradus ad Parnassum (Fux, J. J., 1725), considera um conjunto de regras que definem restrições adicionais a possíveis sequências de intervalos consonantes, sendo a mais importante a proibição de quintas paralelas, ou seja, sequências do tipo $a+\varepsilon 7, b+\varepsilon 7$. De acordo com a perspectiva contrapontística de definir sequências de intervalos, devemos tentar estabelecer uma espécie de tensão entre intervalos consonantes e dissonantes quando passamos de um intervalo para o seguinte. Mas, assumindo um ponto de vista contraditório, devemos permanecer simultaneamente na metade consonante! Este conflito pode ser resolvido introduzindo simetrias de deformação no espaço tangente $Z_{12}[\varepsilon]$. Esta deformação permite-nos «saltar» de uma consonância para outra, mas sob a condição de que a primeira viva na metade consonante deformada, enquanto a outra vive na metade dissonante deformada! Desta forma, modelamos a tensão contrapontística por uma deformação do espaço tangente. Tal como para o modelo de modulação, esta ideia é proveniente da fisica, já que podem surgir forças físicas quando se aplicam simetrias locais a um sistema fisico. Isto pode ocorrer, por exemplo, se se distorcer um balão (basta segurá-lo em ambas as mãos, rodá-lo no sentido dos ponteiros do relógio com a mão direita 
e no sentido contrário com a mão esquerda), o que produz forças de deformação. No caso em análise, as simetrias de deformação podem ser reconhecidas como sendo de facto simetrias locais (Mazzola, G., 1990b) e, portanto, produzem «forças de deformação». No sentido acima indicado, esta abordagem conduz a sequencias permitidas e proibidas de intervalos consonantes (tangentes $a+\varepsilon b$ ) e o resultado é extremamente congruente com as regras de Fux, em particular, aplica-se a regra da proibição das quintas paralelas (Mazzola, G., 1990b).

Mais uma vez, podemos incluir este modelo em generalizações canónicas. As propriedades características de dicotomia consonância/ dissonância podem ser variadas e conduzem a outras cinco classes de dicotomias distintas. Em cada uma delas, o contraponto pode ser executado, o que permite afirmar que a dicotomia clássica consonâncial dissonância está situada numa posição globalmente singular no mundo dos contrapontos potenciais! Mais ainda, e isto cria de certo modo um ambiente mágico, existe uma dicotomia polar $\mathrm{I} / \mathrm{J}$ contra a dicotomia consonância/dissonância que é correctamente definida pelos seis intervalos próprios a partir da tónica da escala maior. Enquanto a escala maior é a mais adequada para executar o contraponto Fux (K/D), uma escala cujos intervalos estão relacionados com $\mathrm{K}$ é a melhor para executar o contraponto $\mathrm{I} / \mathrm{J}$. Por estranho que pareça, esta escala está fortemente relacionada com as escalas usadas nas ragas indianas (Hichert, J., 1993). Assim, concluímos que os modelos matemáticos induzem interessantes variações interculturais e extensões do «melhor de todos os possíveis mundos» da música europeia.

Convém acrescentar que o presente modelo de contraponto foi também sujeito a extensos testes empíricos por electroencefalograma profundo EEG (Mazzola, G., et al., 1989), que revelaram uma resposta significativa das regiões limbica e auditora do cérebro para a simetria autocomplementar.

\section{ESPACOS CONCEPTUAIS UNIFICADOS E SOFTWARE PARA OBJECTOS MUSICAIS}

A variedade de objectos musicais e musicológicos é extremamente rica e diversa. Vimos que diferentes estruturas algébricas e geométricas podem intervir ao nível da harmonia e do contraponto. Quando abandonamos o contexto bem temperado, há ainda outros tipos de módulos que intervêm, e, se tivermos de modelar objectos entre partituras, teoria musical e investigação de execução, a variedade acaba por exceder qualquer modelo 
pré-fixado de dados como os que encontramos em sistemas de organização de bases de dados. Para implementar a teoria musical matemática no software RUBATO ${ }^{\circledast}$ (Mazzola, G., e Zahorka, O., 1996), desenvolvido no Laboratório Multimédia da Universidade de Zurique, este problema teve de ser abordado de modo genérico. Sem entrar em detalhes, apresentamos aqui as ideias principais. Uma vez que a tarefa de construir um modelo de dados «universal» era de facto enciclopédica, os princípios básicos da ciência enciclopédica (Mazzola, G., et al., 1998), em particular a partir da Encyclopédie de Diderot (Auroux, S., 1979), foram considerados e reformulados no contexto do paradigma da programação orientada para objectos. Estes princípios são a unidade, a completude e o discurso. O modelo de dados para um espaço de conceito musical universal implementou (e desenvolveu a um nível matemático teórico, incluindo a teoria de topos, o derradeiro casamento entre a lógica e a geometria (Mac Lane, S., e Moerdijk, I., 1994)) estes princípios da seguinte forma (ver figura 9): a unidade foi traduzida num conceito baseado em recursão, incluindo construção conceptual auto-referencial circular. A condição de completude foi modelada seguindo um arsenal universal de tipos de ramificação (incluindo tudo o que a matemática moderna oferece como construção de objectos universais, ou seja, limites, co-limites e objectos poderosos da teoria do topos). Finalmente, o princípio do discurso foi implementado através da extensibilidade dinâmica e ilimitada do quadro conceptual dado por novas construções, incluindo ordenações canónicas totais entre os objectos existentes.

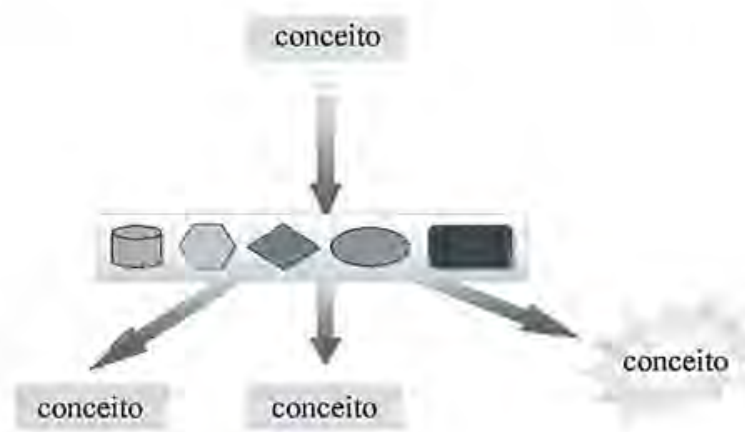

Fig. 9-No design e na teoria de modelos de dados para conceitos musicais, os principios enciclopédicos de unidade, completude e discurso são implementados através da recursividade conceptual (1), de tipos de ramificação universal (2) e da extensibilidade dinâmica sem restriçōes (3) e da ordenaçăo do quadro conceptual 
Em vez de abordarmos definições formais, preferimos ilustrar a construção conceptual para um conceito circular musicalmente importante: a nota estrutural (ver figura 10). O problema reside no facto de muitas vezes, em composição musical, análise e representação, as notas não serem meros objectos, mas permanecerem agrupadas a uma encapsulação hierárquica de objectos delegados de status hierarquicamente inferior, tal como acontece por exemplo, em ornamentos (como os trilos) ou na análise schenkeriana. Num trilo, é-nos dada uma nota que transporta um grupo de notas ornamentais de carácter secundário e que são apenas uma pequena variação da nota âncora (ver figura 10 , em cima à esquerda). $\mathrm{Na}$ análise schenkeriana - também corroborada pela abordagem de Jackendoff-Lerdahl (1983) — de estruturas de agrupamento global em partituras musicais, certas partes da partitura são consideradas uma espécie de desdobramento estrutural construído em torno de notas pivotais de modo recursivo.

Para formalizar esta configuração, o conceito de nota estrutural abarca dois constituintes, uma nota âncora e uma componente satélite. Esta primeira ramificação do conceito é uma espécie de produto cartesiano (mais geralmente, um limite) ou, logicamente falando, uma conjunção de atributos. A componente da nota âncora é a parte inofensiva, uma vez que descreve uma estrutura de nota de piano comum. Uma nota âncora é dada por um produto cartesiano e ramifica-se em intensidade, altura, timbre e duração. Cada um destes atributos é uma construção conceptual de um tipo básico ou simples: timbre refere-se a um número real, altura refere-se a um inteiro (passos de meio-tom), intensidade refere-se a palavras (assentando na álgebra monóide sobre o alfabeto e os inteiros) para deserever indicações do som tais como $m f$,ff, etc., e duração é um número real, tal como a componente timbre.

A parte menos inofensiva é a componente satélite. Esta contém um conjunto finito de objectos (que pode ser vazio), cobrindo objectos delegados como as notas ornamentais do trilo numa configuração hierárquica. No entanto, como a estrutura hierárquica não pode ser forçada a terminar neste ponto, os objectos satélite devem estar abertos a uma eventual delegação mais profunda. Deste modo, qualquer elemento no «saco» satélite deve também ser uma nota estrutural. Isto significa que o conceito de nota estrutural é circular. Mas não se trata necessariamente de uma situação circular para uma instância concreta do conceito de nota estrutural. De facto, a colecção de satélites pode tornar-se o conjunto vazio, e então, não aparecendo indeterminações, a instância do conceito é uma construção finita. No entanto, a existência de um conceito circular de nota estrutural não é um assunto trivial. Podíamos considerar esta 
estrutura como uma teoria de Galois de conceitos, uma vez que estes conceitos podem ser definidos por «equações conceptuais» como números algébricos (tal como $x^{2}+1=0$ para a famosa unidade imaginária). Isto introduz um novo ramo da teoria do topos: a teoria de Galois conceptual (ver Mazzola, G., et al., 2001, para pormenores técnicos).

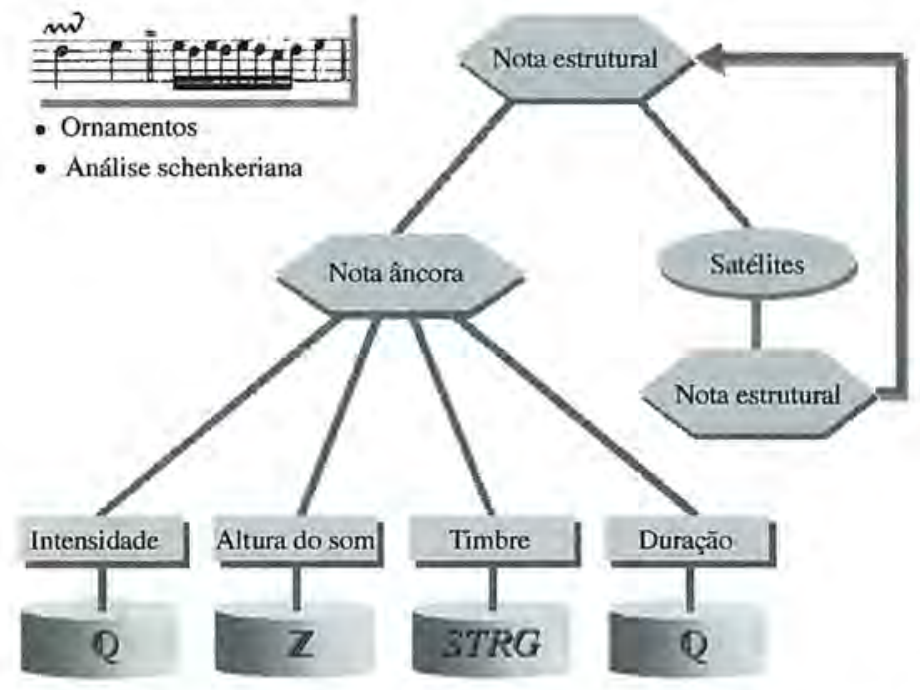

Fig. 10 - Um exemplo notável de uma construção conceptual em música é definido pelo conceito de nota estrutural. Essencialmente, este conceito formaliza estruturas onde temos um objecto âncora rodeado por um agrupamento de «objectos delegados» de hierarquia inferior: Estas construções são necessárias quando se trata de ornamentos gerais (tais como os trilos) ou de análise schenkeriana global de partituras musicais. Neste exemplo, a construção do conceito recursivo cristaliza na componente de satélite do conceito, um atributo que contém objectos da mesma arquitectura a priori, à semelhança da estrutura da nota estrutural inicial

Para além da grande vantagem de poder ser implementada em ambientes de software para computadores, esta linguagem conceptual tem a grande desvantagem de a classificação dos seus objectos se tornar uma tarefa extremamente dificil no campo da matemática abstracta, desde a enumeração simples de todos os casos possíveis até à mais sofisticada determinação de todas as classes de isomorfismos de determinados tipos (Mazzola, G., et al., 2001). 
Mesmo em situações elementares, a variedade de objectos torna-se incrivelmente grande. Vejamos, por exemplo, conceitos tais como os motivos. Um motivo pode ser encarado como um subconjunto do produto cartesiano $\left(\mathrm{Z}_{12}\right)^{2}$, no sentido de a primeira cordenada ser a duração, um inteiro módulo 12 unidades de tempo, enquanto o segundo corresponde à classe de altura do som. Dizemos que dois motivos são equivalentes (isomórficos) se e só se existir um isomorfismo afim do espaço ambiente $\left(\mathrm{Z}_{12}\right)^{2}$ que tranforma um deles no outro (o grupo desses isomorfismos afins consiste em 663552 elementos). A lista de representativos para as 26 classes de isomorfismos para motivos de três elementos foi utilizada em composição (Mazzola, G., 1990a) e análise (Mazzola, G., 1990b) musicais. Isto significa que a classificação é não apenas interessante em termos matemáticos, mas pode também ser utilizada para síntese e análise de composições concretas.

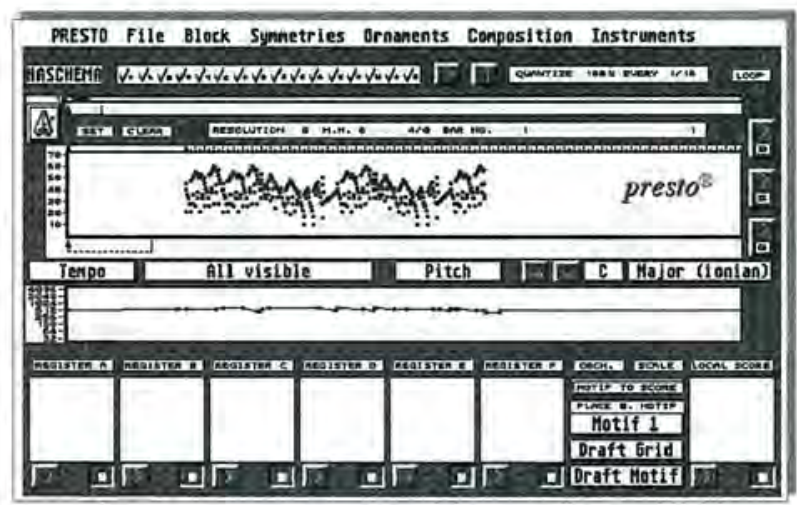

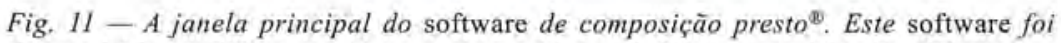
desenvolvido em 1986 segundo uma recomendação de Herbert von Karajan. Fizeram-se vários $C D$ de estilos diferentes (jazz e música contemporânea) utilizando este programa. Foi concebido de modo a permitir a aplicação de ferramentas de construção paradigmáticas da teoria matemática da música, como, por exemplo, transformações de simetria e deformações

A riqueza exorbitante de motivos musicais torna-se evidente quando tentamos contar o número de classes de isomorfismo de motivos de 72 elementos em $\left(\mathrm{Z}_{12}\right)^{2}$ (metade da cardinalidade do espaço ambiente). 
Com base na teoria da enumeração de Polya e de de Bruijn, Harald Fripertinger (1993) conseguiu contá-los, tendo obtido o número

\section{$2230741522540743033415296821609381912 \approx 2.23 \times 10^{36}$}

enquanto o número de estrelas numa galáxia média não excede $10^{t i}$. Deste modo, temos ainda algumas opções composicionais.

A figura 11 mostra uma interface principal do software comercial para composição presto ${ }^{(2)}$ (Mazzola, G., 1990b), que foi implementado e aperfeiçoado no periodo de 1986 a 1994 em computadores Atari sob recomendação de Herbert von Karajan. Utilizando este software, fizeram-se vários $\mathrm{CD}$, entre os quais um CD de jazz no qual se utilizou a classificação de motivos de três elementos. Os críticos de jazz não reconheceram a composição para piano, percussão e guitarra eléctrica como sendo música digitalmente gerada e executada.

O software que executa o quadro conceptual acima referido é uma versão aperfeiçoada do software RUBATO ${ }^{\circledR}$. Actualmente, está a ser desenvolvido por dois grupos de investigação, um na Universidade Técnica de Berlim (www.mamuth.de) e o outro no Laborátório Multimédia da Universidade de Zurique (www.encyclospace.org). A nova versão do RUBATO $^{\circledR}$ funciona na tecnologia Mac OS X e utiliza o sistema UNIX, bem como componentes de software baseados em JAVA (estes últimos concebidos para navegação visual na Internet). Inclui componentes analíticas (análise rítmica, melódica, harmónica), uma componente composicional (de facto, um melhoramento do antigo presto ${ }^{\mathscr{B}}$ ), um módulo de execução, módulos de filtragem para diferentes formatos de importação/exportação e análise lógica de construções conceptuais (ver www.mamuth.de, e www.encyclospace.org). A figura 12 apresenta a arquitectura global do RUBATO ${ }^{\circledR}$. Mostra-se aqui uma janela de aplicação principal do DBMS (Data Base Management System: sistema de gestão de bases de dados) deduzida a partir da presente estrutura conceptual; a terminologia técnica é «forma» para espaços ambientes que incluem itens conceptuais, enquanto os últimos se designam por «denotadores» e representam uma espécie de ponto no seu espaço de formas ambiente. Adiciona-se um número de módulos dinamicamente carregáveis, os chamados RUBETTES ${ }^{\circledR}$, à aplicação básica. A natureza universal dos modelos de dados permite a transferẽncia sem restrições de dados entre quaisquer dois desses RUBETTES ${ }^{\circledR}$.

Deve salientar-se que uma tal plataforma de software avançado é a base de um novo estilo de investigação interactiva. O RUBATO ${ }^{\mathscr{V}}$ parece, de facto, um grande edificio onde trabalham diferentes especialistas e onde 
o modelo de dados constitui uma base de linguagem comum. Assim, a unificação de diferentes aspectos de música e da investigação em música ocorre também ao nível tecnológico, ao nível da infraestrutura de colaboração e, em última análise, do estilo científico.

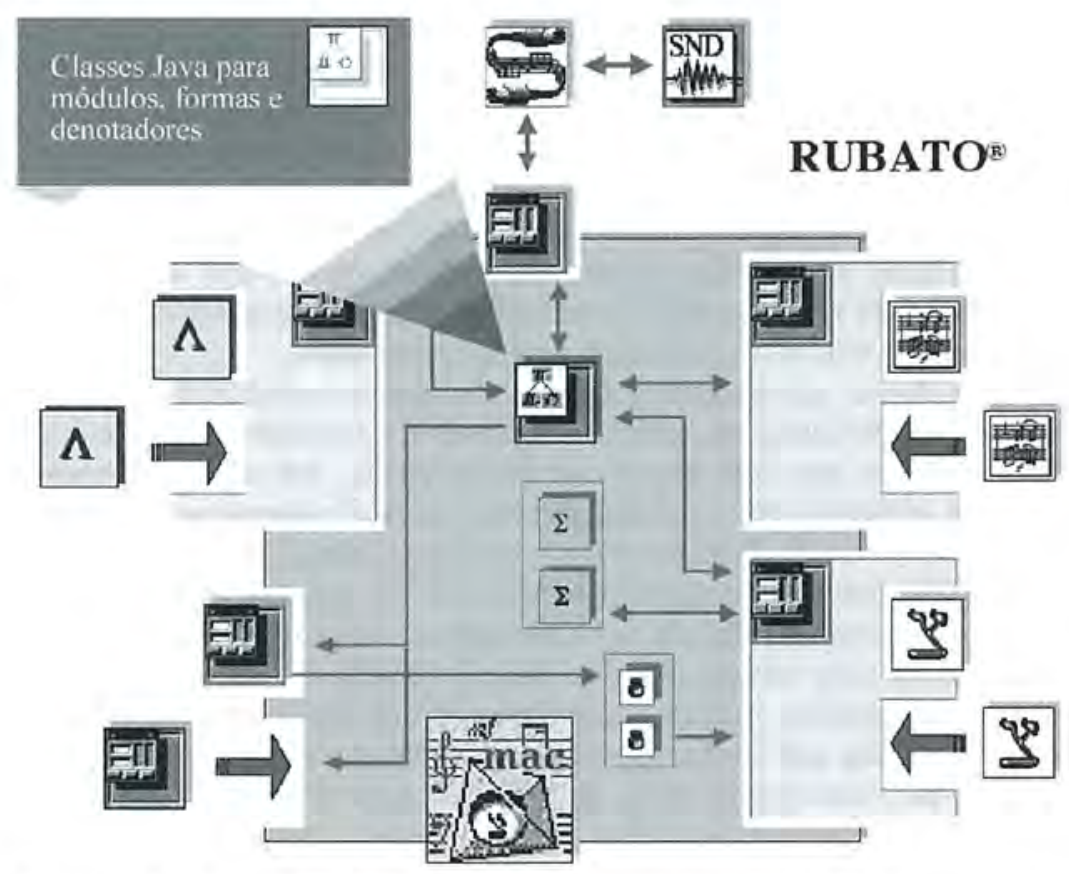

Fig. 12-O software RUBATO ${ }^{*}$ executando sobre a tecnologia Mac OS X é construido a partir de uma aplicação principal (rectângulo grande indentado) e de um número variável de módulos dinamicamente carregáveis, os RUBETTES ${ }^{\star}$, concebidos para análise, composição, execução, filtragem de formato e análise conceptual lógica. O sistema de base de dados também pode ser executado em JAVA e foi concebido para navegação visual em sites da Internet

\section{CAMPOS de Vectores de EXECUÇÃo}

Finalizamos esta exposição com uma breve descrição do módulo de execução RUBETTE ${ }^{\circledR}$, do RUBATO ${ }^{\circledR}$, já que ele é representativo do nível analítico e dos diversos tipos de dados do enquadramento conceptual 
global. Não podemos abordar em pormenor esta matéria, por isso restringimo-nos a uma apresentação geral qualitativa. A ideia que está na base deste módulo é a de que a execução de uma determinada partitura pode ser dirigida pelo uso de resultados analíticos sobre essa partitura; esta é a abordagem clássica adoptada pelo músico e filósofo Theodor W. Adorno (1956). Isto não significa que a motivação emocional ou gestual não seja importante, mas actualmente a análise é a mais desenvolvida componente critica da execução. Para compreender a natureza da execução, temos de ter consciência de que se trata de uma transformação do nível simbólico de objectos da partitura para o nível físico de eventos sonoros (ver figura 13).

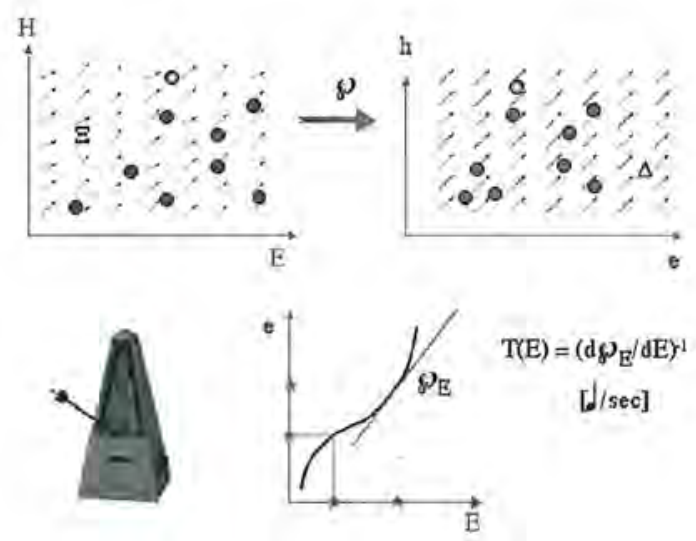

Fig. 13 - A execução é uma transformação $\wp$ de uma realidade simbólica da partitura para a realidade fisica dos eventos acústicos. A transformação pode ser descrita pela sua derivada, como se ilustra na metade inferior desta figura. No caso do tempo de duração, a derivada é aquilo de que precisamos para definir tempo musical. A duração fisica é obtida do tempo por uma integração. Quando consideramos vários parâmetros de tom, tem de se generalizar a curva tempo a um campo de execuçâo $X$ (em cima à esquerda) cujo integral conduz à transformação execução

A transformação execução $\wp$ pode ser descrita pelo campo de imagem inversa $\Xi$ do campo diagonal $\Delta=(1, \ldots, \mathrm{I})$ no espaço físico (em cima à direita na figura 13). No caso de uma execução conduzida por uma análise A, este campo $\Xi$ é deformado de acordo com operadores específicos $\Omega$, conduzindo a um novo campo $\Xi^{*}=\Omega(\Xi, A)$. Por exemplo, operadores de 
tempo actuam na componente de tempo de $\Xi$, enquanto operadores de afinação actuam na componente altura ${ }^{6}$ de $\Xi$.

O conceito de análise no software RUBATO ${ }^{\circledR}$ foi especificado de modo que a análise seja representada por uma função de ponderação numérica das notas, das barras de compasso, das pausas, etc., da partitura dada. Esta exigência garante que os operadores de execução podem ser construídos a partir de dados numéricos e não a partir de textos difusos tradicionais em teoria musical. Cada RUBETTE ${ }^{\otimes}$ analítico conduz a tais funções de ponderação. Esta metodologia proporcionou-nos execuções muito interessantes e convincentes de diversas peças, em particular do Contrapuntus III da Arte da Fuga, de Johann Sebastian Bach (Stange-Elbe, J., 2000).

\section{Referências}

Adorno, Th. W., (1956) - Fragment über Musik und Sprache. Stuttgart, Jahresring Auroux, S., (1979) - La sémiotique des encyclopédistes. Payot, Paris

Barrow, J., e Tipler, F., (1986) - The Anthropic Cosmological Principle: Oxford University Press, Nova Iorque

Fripertinger, H., (1993) - Endliche Gruppenaktionen in Funktionenmengen - Das

Lemma von Burnside - Repräsentantenkonstruktionen - Anwendungen in der Musiktheorie. Dissertação de doutoramento, Univ. Graz

Fux, J. J., (1742) - Gradus ad Parnassum (1725). Dt. und kommentiert von L. Mitzler, Leipzig

Hichert, J., (1993) - Verallgemeinerung des Kontrapunkttheorems für die

Hierarchie aller starken Dichotomien in temperierter Stimmung. Dissertação de licenciatura, TU Ilmenau

Jackendoff, R., e Lerdahl, F., (1983) - A Generative Theory of Tonal Music. MIT

Press, Cambridge MA

Mac Lane, S., e Moerdijk, I., (1994) - Sheaves in Geometry and Logic. Springer,

Nova Iorque

Mazzola, G., (1990a) - SYNTHESIS, StoA music, Zurique

Mazzola, G., (1990b) - Geometrie der Töne. Birkhăuser, Basileia

Mazzola, G., et al. (1998) - Humanities@Encyclospace. Schweizerischer

Wissenschaftsrat, www.encyclospace.org, Berna

Mazzola, G., et al. (2001) - The Topos of Music. To appear, Birkhäuser, Basileia

${ }^{6}$ Notemos que, em geral, campos de execução não são produtos cartesianos de factores unidimensionais. 
Mazzola, G., et al. (1989) - A Symmetry-Oriented Mathematical Model of Classical Counterpoint and Related Neurophysiological Investigations by Depth-EEG. In: Hargittai I (ed.): Symmetry II, CAMWA, Pergamon, Nova Iorque

Mazzola, G., e Zahorka, O., (1996) - RUBATO on the Internet (www.rubato.org). Univ. Zurique

Muzzulini, D., (1995) - Musical Modulation by Symmetries. J. for Music Theory Noll, Th., (1995) - Morphologische Grundlagen der abendländischen Harmonik. Dissertação de doutoramento, TU Berlim

Schönberg, A., (1966) - Harmonielehre (1911). Universal Edition, Viena

Stange-Elbe, J., (2000) - Analyse- und Interpretationsaspekte zu J. S. Bachs Kunst der Fuge mit Werkzeugen der objektorientierten Informationstechnologie.

U Osnabrück, Osnabrück

Ver www.mamuth.de (site of the KiTMaMuTh research group for mathematical music theory at TU Berlin, director: Thomas Noll)

Ver link em www.encyclospace.org to the Multimedia Lab of U Zurich 


\section{$\begin{array}{llllll}\text { C I E } & \mathbf{N} & \mathbf{C} & \mathbf{A}\end{array}$}

mitiram realizar com sucesso tarefas tão distintas como a programação de um voo a Marte, a previsão de resultados eleitorais, a explicação do funcionamento de alguns mecanismos do sistema nervoso, ou a abordagem critica de obras de arte e de textos literários. Da ciência à sociedade, dos grandes avanços técnicos à solidez de uma argumentação lógica, a Matemática constrói teias de uma imensa flexibilidade resultante do carácter universal da sua linguagem.

Neste livro, personalidades de diferentes universos dão o seu testemunho sobre a forma como usam as teias matemáticas para tecer a sua própria visão do mundo.

Maria Paula Serra de Oliveira é professora de Matemática na Faculdade de Ciências e Tecnologia da Universidade de Coimbra. 